\title{
Prevalence of undetectable
} and suppressed viral load in HIV-infected pregnant women initiating Option $\mathrm{B}+$ in Uganda: an observational study nested within a randomized controlled trial

Grace Gabagaya', Gordon Rukundo', Alexander Amone1, Priscilla Wavamunno', Joyce Namale-Matovu', Irene Lubega', Clemensia Nakabiito', Zikulah Namukwaya', Monica Nolan', Samuel S. Malamba², Rachel King³, Jaco Homsy ${ }^{3}$, Mary Glenn Fowler ${ }^{4}$ and Philippa Musoke ${ }^{1,5^{*}}$

\begin{abstract}
Background: Viral load (VL) testing is key in monitoring adherence to antiretroviral therapy (ART) and documenting HIV treatment response. As per HIV treatment guidelines in Uganda, the first VL test is recommended 6 months after initiation of ART. Undetectable VL ( $U V L$ ) at ART initiation may be helpful in detecting elite controllers in the absence of previous ART use. We investigated viral suppression at ART initiation among a cohort of HIV-positive pregnant women enrolled in the Friends for Life Circles (FLC) for Option B+ randomized controlled trial (RCT).

Methods: Pregnant women $\geq 18$ years of age testing positive for HIV at their first antenatal care visit and starting on ART Option B+ as per the National PMTCT Program guidelines were enrolled into the FLC for Option B+ RCT in urban Kampala and rural Mityana districts of Uganda. Each participant had whole blood samples collected at enrolment to assess baseline VL. Plasma HIV-1 RNA was quantified using COBAS Ampliprep /COBAS Taqman. Baseline VL below 400 RNA copies/ml was considered as viral suppression while baseline VL below 20 RNA copies/ml was considered uVL.

Results: The mean duration from the date of ART initiation to time of sample collection for baseline VL assessment was 4.4 days (SD 3.6). Of the $532 \mathrm{HIV}$-positive pregnant women enrolled in the FLC for Option B+ study and newly starting Option B+ without a self-reported history of prior ART use, 29 (5.5\%) had uVL and 113 (21.4\%) had suppressed VL at baseline. There was no association between participants'age, gravidity, marital status, mean monthly income, educational level, disclosure of HIV status to partner, and UVL or viral suppression at baseline. However, nondisclosure of HIV status to any other person was associated with decreased odds of viral suppression at baseline (OR 0.640; 0.416-0.982).
\end{abstract}

Conclusion: Twenty-one percent of HIV-positive Ugandan pregnant women initiating ART (Option B+) showed virological suppression at baseline and were presumed to be "elite controllers" or to have misreported being ART-naive.

*Correspondence: pmusoke@mujhu.org

${ }^{1}$ Makerere University - Johns Hopkins University Research Collaboration,

P.O. Box 23491, Kampala, Uganda

Full list of author information is available at the end of the article original author(s) and the source, provide a link to the Creative Commons licence, and indicate if changes were made. The images or other third party material in this article are included in the article's Creative Commons licence, unless indicated otherwise in a credit line to the material. If material is not included in the article's Creative Commons licence and your intended use is not permitted by statutory regulation or exceeds the permitted use, you will need to obtain permission directly from the copyright holder. To view a copy of this licence, visit http://creativecommons.org/licenses/by/4.0/. The Creative Commons Public Domain Dedication waiver (http://creativeco mmons.org/publicdomain/zero/1.0/) applies to the data made available in this article, unless otherwise stated in a credit line to the data. 
Further studies are needed to better understand the biologic mechanisms of elite controllers among pregnant women as well as to differentiate elite controllers from concealed ART use.

Trial Registration The trial was registered as NCT02515370 (04/08/2015) on Clinicaltrials.gov.

Keywords: HIV, Pregnancy, Viral load, Viral or virological suppression, Uganda, HIV transmission, Option B+, Antiretroviral therapy

\section{Background}

Viral load testing is the gold standard for HIV treatment monitoring and is recommended as the preferred approach to diagnose and confirm treatment failure $[1,2]$. The WHO recommends that routine VL testing should be done at 6 and 12 months after initiation of ART for adult HIV patients and every 12 months thereafter if the patient is stable on ART [1].

Given that VL assessment is not done routinely at ART initiation, ART-naïve HIV-infected individuals with suppressed or undetectable VL (uVL) are not identified. Detecting suppressed/undetectable VL in HIV-infected individuals newly initiating ART may be useful in identifying "elite controllers" or unreported ART use. In this paper, we analysed the prevalence of virological suppression at ART initiation among a cohort of HIV-positive pregnant women enrolled in the Friends for Life Circles (FLC) for Option B+ randomized controlled trial (RCT).

\section{Methods}

\section{Study design and population}

The FLC for Option B+ study was an open-label RCT with two parallel intervention and control arms. This RCT was undertaken in South Central Uganda, at Mulago National Referral Hospital and Kampala Capital City Authority (KCCA) health units in Kampala (urban) district as well as at Mityana District hospital and six surrounding health centers in Mityana (rural) district. The RCT goal was to test an enhanced peer group support system called "Friends for Life Circles" (FLCs) to help HIV-infected pregnant women initiating PMTCT Option $\mathrm{B}+$ during the antenatal period adhere to lifelong ART and postpartum care visits [3]. Eligible participants were HIV-positive pregnant women $\geq 18$ years of age, newly initiating ART Option $\mathrm{B}+$, who agreed to come to the study clinic for scheduled appointments and to be home visited as needed to ensure follow up [3]. In this RCT, ART-naïve women were defined as those who started on ART on or shortly ( $\leq 14$ days) before their enrolment into the FLC Option B+ trial. Additional inclusion criteria included residing within a $20 \mathrm{~km}$ radius around the study clinic and not planning to move out of the catchment area within the next 2 years [3]. Exclusion criteria included any medical, social or other circumstancse that might prevent a mother from adhering to the study protocol [3]. At trial commencement, the study relied on documented pregnancy and positive HIV test from the health units which resulted in enrolment of some participants that were neither pregnant nor HIV positive. The protocol was subsequently amended so that confirmatory testing for pregnancy and HIV positivity could be done by the study prior to enrolment.

\section{Data collection procedures}

Pregnant women testing HIV-positive and started on ART on the same day as part of the National PMTCT Program were screened for the RCT. Eligible women were enrolled and randomized into the RCT within 14 days of ART initiation. At enrolment into the RCT, each participant had whole blood samples collected for assessment of baseline plasma HIV-RNA as well as standardized questionnaires administered to capture data on socio-demographic characteristics, adherence to ARVs and HIV status disclosure.

\section{Blood sample collection and HIV testing}

Whole blood collected in sterile EDTA tubes was stored at room temperature. Plasma was then separated from whole blood by centrifugation within $24 \mathrm{~h}$ of sample collection after which plasma was transferred to sterile cryovials. In Kampala, processing and storage was done at the VL testing Laboratory while in Mityana, plasma was stored frozen at $-20{ }^{\circ} \mathrm{C}$ in the Mityana Hospital Laboratory and transported to Kampala for storage and VL testing every 1-2 weeks on frozen icepacks in temperature-controlled cool boxes. Plasma VL testing was conducted in batches at the Infectious Disease Institute (IDI) Core Lab in Mulago Hospital using COBAS Ampliprep / COBAS Taqman HIV-1 test whose lower limit of detection was 20 copies $/ \mathrm{ml}$. Participants in whom no viral copies were detected had repeat rapid HIV antibody testing done to confirm HIV diagnosis and if found negative, had HIV DNA PCR testing done. Undetectable viral load in this study was defined as VL count $<20$ copies $/ \mathrm{ml}$ while virological suppression was defined as $\mathrm{VL}$ count $<400$ copies/ml. 


\section{Statistical analysis}

STATA software (StataCorp LP, 4905 Lakeway Drive, College Station, TX, USA) was used for all statistical analyses. All collected data on socio-demographic variables were considered for inclusion in the univariate logistic regression analysis and variables with a significance level of $\mathrm{p}<0.1$ were considered for inclusion in the full multivariate model. Using a backward elimination method, only variables with a significance level of $\mathrm{p}<0.05$ were kept in the final model. Odds ratios were used to measure the magnitude of the effect and a Wald test was used to evaluate the statistical significance of each coefficient in the model assessing the relationship between sociodemographic characteristics and the different binary viral load outcome groups $[(0=$ detectable $\mathrm{VL}, 1=$ undetectable VL) or $(0=$ unsuppressed VL, $1=$ suppressed VL)]. The likelihood ratio test (LHRT) was used to compare the goodness of fit for two nested models.

\section{Results}

A total of $540 \mathrm{HIV}$-positive pregnant women participants were enrolled into the FLC for Option B+ RCT between May 2016 and September 2017. Of these, eight participants were subsequently terminated due to inappropriate enrolment and are excluded from the data analyses. Three of these did not disclose information on ineligibility status during screening while five of these were found to be neither pregnant nor HIV-positive upon confirmatory testing.

The mean duration from date of ART initiation to time of sample collection for baseline VL assessment was 4.4 days (SD 3.6) and the median was 4 days (range 0-30 days, IQR 2-6 days). Table 1 shows the univariate analysis of the proportions of the 532 eligible study participants with baseline suppressed (<400 copies/ml) and undetectable $(<20$ copies/ml) HIV VL by socio-demographics characteristics.

Participants' median age was 25 years; 137 (25.8\%) were from rural Mityana and 395 (74.2\%) from urban Kampala. Twenty-nine (5.5\%) of 532 enrolled women had baseline uVL (<20 copies/ml) and 84 (15.8\%) had baseline viral suppression (20-399 copies/ml), all with no self-reported prior ART use. Therefore, the prevalence of undetectable VL was $5.5 \%$ and the proportion of patients with suppressed VL (<400 copies $/ \mathrm{ml})$ was $21.2 \%$. The median VL counts and frequencies of the different VL categories by RCT site are summarized in Table 2 .

The median age in years for participants with and without uVL at baseline was 25 (IQR: 21, 30) and 25 (IQR: 22, $30)$ respectively. The multivariate analysis (Table 3 ) shows that disclosure of HIV status to any person other than a partner was the only factor associated with baseline VL suppression $(\mathrm{VL}<400$ copies $/ \mathrm{ml})$; there was no association between gravidity, marital status, religion, tribe, mean monthly income, educational level attained, disclosure of HIV status to partner and $\mathrm{UVL}$ (VL $<20$ copies/ $\mathrm{ml})$ or VL suppression ( $\mathrm{VL}<400$ copies $/ \mathrm{ml}$ ) at baseline as illustrated in Table 3. The adjusted odds ratio for VL suppression (<400 copies/ml) in those who did not disclose compared to those who disclosed to any person other than their partner was 0.640 (95\% CI 0.416-0.982, $\mathrm{p}=0.041$ ), after adjusting for marital status. (Table 3 ).

\section{Discussion}

Our results show that $5.5 \%$ of HIV-infected pregnant women who initiated ART in the study had UVL at baseline and were potential elite controllers (EC). This is higher than previous findings in Uganda where a prevalence of $1 \%$ and $0.26 \%$ of HIV controllers (ECs and aviraemic controllers) were reported by Laeyendecker et al. [4] and Kayongo et al. [5] in 2009 and 2018 respectively. However, our findings are consistent with the findings of a 2014 systematic review where the proportion of ECs was $0.15-7.7 \%$ and did not necessarily reflect the length of follow-up [6].

ECs are HIV-positive individuals who are able to suppress viral replication to undetectable levels for extended periods of time without ART. This definition of elite controllers thus requires factoring in longitudinal characteristics of VL suppression over a certain period of time $[6,7]$, which was not documented in our study since it was a baseline analysis. ECs are believed to control viral replication through mechanisms involving host immune responses [6]. Consistent with our findings, previous reports have not documented any association between elite controllers and specific socio-demographic characteristics [7].

We also identified a high proportion of women who were virally suppressed $(<400$ copies $/ \mathrm{ml})$ at baseline $(\mathrm{N}=113,21.2 \%)$. This is in contrast to the HPTN068 study [8] which, in spite of using a higher threshold for viral suppression (<2000 copies/ml), had only $15.7 \%$ of patients virally suppressed in the absence of ART. In our study, women who had not disclosed to an other person than their partner were less likely to be virally suppressed (OR 0.64; 95\% CI 0.416-0.982, $\mathrm{p}=0.041$ ) than those who had disclosed. It is difficult to interpret this finding without more information but disclosure of HIV remains a challenge in Uganda because of stigma, particularly for women bearing children for fear of the consequences such women might face from their partner or others [9]. It might indicate that some of these women have been infected for some time and did not disclose nor get 
Table 1 Proportions of pregnant women with baseline suppressed and undetectable HIV viral load by socio-demographic characteristics

\begin{tabular}{|c|c|c|c|c|c|c|c|c|}
\hline \multirow[t]{2}{*}{ Characteristics } & \multirow[t]{2}{*}{$\mathrm{N}=532$} & \multirow[t]{2}{*}{ Column \% } & \multicolumn{2}{|c|}{$\begin{array}{l}\text { Suppressed VL }(<400 \\
\text { copies } / \mathrm{ml})\end{array}$} & \multirow[t]{2}{*}{$p$-value } & \multicolumn{2}{|c|}{$\begin{array}{l}\text { Undetectablevl }(<20 \\
\text { copies } / \mathrm{ml})\end{array}$} & \multirow[t]{2}{*}{ p-value } \\
\hline & & & $\mathbf{n}$ & Row\% & & $\mathrm{n}$ & Row\% & \\
\hline \multicolumn{9}{|l|}{ Site } \\
\hline Urban-Kampala & 395 & 74.2 & 87 & 22.0 & & 19 & 4.8 & \\
\hline Rural-Mityana & 137 & 25.8 & 26 & 19.0 & 0.452 & 10 & 7.3 & 0.269 \\
\hline \multicolumn{9}{|l|}{ Age in years } \\
\hline $18-24$ & 256 & 48.1 & 57 & 22.3 & & 13 & 5.1 & \\
\hline $25-34$ & 238 & 44.8 & 50 & 21.0 & & 14 & 5.9 & \\
\hline $35-44$ & 38 & 7.1 & 6 & 15.8 & 0.314 & 2 & 5.3 & 0.924 \\
\hline \multicolumn{9}{|l|}{ Marital status } \\
\hline Married/co-habiting & 424 & 79.7 & 89 & 21.0 & & 25 & 5.9 & \\
\hline Never married & 85 & 16.0 & 23 & 27.1 & & 4 & 4.7 & \\
\hline Separated/divorced/widowed & 23 & 4.3 & 1 & 4.4 & 0.483 & 0 & 0.0 & 0.454 \\
\hline \multicolumn{9}{|l|}{ Educational level } \\
\hline University/College/Tertiary & 24 & 4.5 & 3 & 12.5 & & 0 & 0.0 & \\
\hline Secondary ${ }^{\mathrm{b}}$ & 257 & 48.3 & 57 & 22.2 & & 15 & 5.8 & \\
\hline Primary ${ }^{\mathrm{b}}$ & 228 & 42.9 & 48 & 21.1 & & 13 & 5.7 & \\
\hline No formal education & 23 & 4.3 & 5 & 21.7 & 0.422 & 1 & 4.4 & 0.673 \\
\hline \multicolumn{9}{|l|}{ Religion } \\
\hline Catholic & 200 & 37.6 & 46 & 23.0 & & 10 & 5.0 & \\
\hline Protestant & 123 & 23.1 & 26 & 21.1 & & 10 & 8.1 & \\
\hline Moslem & 109 & 20.5 & 20 & 18.4 & & 6 & 5.5 & \\
\hline SDA/Pentecostal/others & 100 & 18.8 & 21 & 21.0 & 0.076 & 3 & 3.0 & 0.398 \\
\hline \multicolumn{9}{|l|}{ Tribe } \\
\hline Non-Ganda & 235 & 44.2 & 55 & 23.4 & & 13 & 5.5 & \\
\hline Ganda & 297 & 55.8 & 58 & 19.5 & 0.775 & 16 & 5.4 & 0.942 \\
\hline \multicolumn{9}{|l|}{ Gravidity } \\
\hline 1 & 100 & 18.8 & 23 & 23.0 & & 2 & 2.0 & \\
\hline 2 & 127 & 23.9 & 31 & 24.4 & & 11 & 8.7 & \\
\hline 3 & 140 & 26.3 & 29 & 20.7 & & 9 & 6.4 & \\
\hline $4+$ & 165 & 31.0 & 30 & 18.2 & 0.353 & 7 & 4.2 & 0.134 \\
\hline \multicolumn{9}{|l|}{ Disclosure to partner } \\
\hline Yes & 213 & 40.0 & 52 & 24.4 & & 13 & 6.1 & \\
\hline No & 302 & 56.8 & 58 & 19.2 & & 16 & 5.3 & \\
\hline No partner & 17 & 3.2 & 3 & 17.7 & 0.424 & 0 & 0.0 & 0.557 \\
\hline \multicolumn{9}{|l|}{ Disclosure to other } \\
\hline Yes & 201 & 37.8 & 52 & 25.9 & & 15 & 7.5 & \\
\hline No & 331 & 62.2 & 61 & 18.4 & 0.066 & 14 & 4.2 & 0.111 \\
\hline \multicolumn{9}{|l|}{ Having any source of income $e^{c}$} \\
\hline No & 309 & 58.2 & 67 & 21.7 & & 19 & 6.2 & \\
\hline Yes & 222 & 41.8 & 45 & 20.3 & 0.694 & 9 & 4.1 & 0.287 \\
\hline Total & 532 & 100.0 & 113 & 21.3 & & 29 & 5.5 & \\
\hline
\end{tabular}

a All 532 study participants included in the analysis were started on ART 30 days or less before being bled for VL count. The median number of days from ART initiation to enrolment was 4 days (Range $0-30$ days, IQR: 2-6 days); the mean was 4.4 days (SD: 3.6). The 8 individuals who were inappropriately enrolled in the study are excluded from this analysis

${ }^{b}$ Partial or completed level of education

c One study participant had no information on source of income 
Table 2 Baseline VL and distribution of pregnant women across VL ranges in Kampala and Mityana districts

\begin{tabular}{|c|c|c|c|c|c|c|}
\hline \multirow[t]{2}{*}{ Baseline VL counts and distribution } & \multicolumn{2}{|c|}{$\begin{array}{l}\text { Enrolled women in Kampala } \\
\text { (urban) }\end{array}$} & \multicolumn{2}{|c|}{$\begin{array}{l}\text { Enrolled women in Mityana } \\
\text { (rural) }\end{array}$} & \multicolumn{2}{|c|}{$\begin{array}{l}\text { All enrolled women } \\
\text { (urban \& rural) }\end{array}$} \\
\hline & \multicolumn{2}{|c|}{$3695(588-18,366)$} & \multicolumn{2}{|c|}{$7585(1001-33,081)$} & \multicolumn{2}{|c|}{$4480.5(638-21,420.5)$} \\
\hline $\begin{array}{l}\text { Distribution of women across different } \mathrm{VL} \text { ranges } \\
\text { (cpml) }\end{array}$ & $N=395$ & Column (\%) & $N=137$ & Column (\%) & $N=532$ & Column (\%) \\
\hline$<20$ & 19 & 4.8 & 10 & 7.3 & 29 & 5.5 \\
\hline 20-399 & 68 & 17.2 & 16 & 11.6 & 84 & 15.8 \\
\hline 400-999 & 34 & 8.6 & 8 & 5.8 & 42 & 7.9 \\
\hline$\geq 1000$ & 274 & 69.4 & 103 & 75.2 & 377 & 70.9 \\
\hline
\end{tabular}

appropriate care and treatment for fear of discrimination from their social network [10].

It is also possible the women failed to report prior ART use since our findings are based on self-report. Much as we found no association between gravidity and VL suppression, there is a possibility that women with previous pregnancies after 2012 when Uganda rolled out Option B, could have received ART for PMTCT and developed viral suppression. Findings elsewhere have documented under-reporting of ART use by HIV patients [11-13]. In South Africa, blood donors reporting no history of ART use and identified as HIV-positive with undetectable viral load, were presumed ECs. However, when plasma samples of these presumed ECs were later tested for ARVs, undisclosed ART use was discovered in $66.4 \%$ of participants [11].

In addition to stigma mentioned above, other possible reasons why women may not report prior ART use are that they may have defaulted on their ART regimen and are thus concerned about being reprimanded. Additionally, participation in a study often implies better care which may prompt women to conceal prior ART use.

Our study had a number of strengths: first, the sample size was relatively large and included both rural and urban Ugandan populations, which increases the generalizability of our results in Uganda. Second, we used a highly sensitive validated assay for measurement of viral load and thus were able to measure VL copies at a very low level of detection. Finally, we were able to conduct HIV DNA PCR testing to confirm HIV status and to guard against including women incorrectly diagnosed as HIV positive based on a falsely positive rapid HIV screening test.

Our study however had some limitations. First, plasma drug levels were not yet available prior to ART initiation and baseline hair collection for measurement of ARV drug concentrations was not done. Baseline hair samples would have been helpful in assessing prolonged ARVs exposure and validation of ART naïve self-reports. Also, baseline VL assessment was done after ART initiation which could raise the question as to whether these women were truly ART-naive at the time of VL measurement. However, the mean duration from date of ART initiation to time of blood sample collection was 4.4 days (median 4 days, range $0-30$ days, IQR 2-6 days) which is very unlikely to have impacted VL measurements, as a period of 5 to 15 weeks has been reported as time to uVL after initiation of ART among HIV-infected pregnant women [14]. We also did not have data on CD4 levels because, since the adoption of Option B+ for PMTCT and the introduction of test and treat HIV policy in Uganda, ART is initiated immediately after confirming HIV infection without the need to measure CD4 levels. Additionally, our multivariate analysis only evaluated suppressed viral load $(<400$ copies $/ \mathrm{ml}$ ) but not undetectable viral load because of small numbers in the undetectable category $(<20$ copies/ml + TND). Lastly, much as partner and relatives' HIV and ART status are important determinants of viral suppression, we did not have these data. This is incumbent on the premise that HIV disclosure and stigma are still challenges and many pregnant women do not share this information.

\section{Conclusions}

In the FLC for Options B+ RCT, over $5 \%$ of pregnant HIV-positive women initiating ART (Option $\mathrm{B}+$ ) had undetectable viral load at baseline and were presumed to be either potential "elite controllers" or did not report previous use of ART. No specific maternal sociodemographic factors aside from disclosure of HIV status to person others than their partner was associated with baseline uVL. Further studies are needed to better understand the biological mechanisms of pregnant women who may be elite controllers; as well as the need and feasibility of screening for baseline antiretroviral drug detection among self-reporting ART-naïve 
Table 3 Multivariate analysis of factors associated with baseline VL suppression in FLC for Option B+ RCT participants

\begin{tabular}{|c|c|c|c|c|}
\hline Characteristics & $\begin{array}{l}\text { Unadjusted OR } \\
(95 \% \mathrm{Cl})\end{array}$ & p-value & $\begin{array}{l}\text { Adjusted OR } \\
(95 \% \mathrm{Cl})\end{array}$ & p-value \\
\hline \multicolumn{5}{|l|}{ Site } \\
\hline Urban-Kampala & 1.000 & & & \\
\hline Rural-Mityana & $0.829(0.509-1.352)$ & 0.453 & & \\
\hline \multicolumn{5}{|l|}{ Age } \\
\hline 18-24 years & 1.000 & & & \\
\hline $25-34$ years & $0.929(0.605-1.425)$ & 0.735 & & \\
\hline $35+$ years & $0.655(0.261-1.643)$ & 0.367 & & \\
\hline \multicolumn{5}{|l|}{ Marital status } \\
\hline Married/co-habiting & 1.000 & & 1.000 & \\
\hline Never married & $1.396(0.820-2.378)$ & 0.219 & $1.275(0.742-2.192)$ & 0.379 \\
\hline Separated/divorced/widowed & $0.171(0.023-1.287)$ & 0.086 & $0.153(0.020-1.156)$ & 0.069 \\
\hline \multicolumn{5}{|l|}{ Educational level } \\
\hline University/College/Tertiary & 1.000 & & & \\
\hline Secondary ${ }^{\mathrm{b}}$ & $1.995(0.574-6.928)$ & 0.277 & & \\
\hline Primary ${ }^{\mathrm{b}}$ & $1.867(0.534-6.521)$ & 0.328 & & \\
\hline No education & $1.944(0.407-9.287)$ & 0.405 & & \\
\hline \multicolumn{5}{|l|}{ Religion } \\
\hline Catholic & 1.000 & & & \\
\hline Protestant & $0.897(0.521-1.546)$ & 0.696 & & \\
\hline Moslem & $0.752(0.419-1.352)$ & 0.341 & & \\
\hline SDA/Pentecostal/others & $0.890(0.497-1.594)$ & 0.695 & & \\
\hline \multicolumn{5}{|l|}{ Tribe } \\
\hline Non-Ganda & 1.000 & & & \\
\hline Ganda & $0.794(0.524-1.204)$ & 0.278 & & \\
\hline \multicolumn{5}{|l|}{ Gravidity } \\
\hline 1 & 1.000 & & & \\
\hline 2 & $1.081(0.583-2.000)$ & 0.804 & & \\
\hline 3 & $0.875(0.471-1.625)$ & 0.672 & & \\
\hline $4+$ & $0.744(0.404-1.371)$ & 0.343 & & \\
\hline \multicolumn{5}{|l|}{ Disclosure to partner } \\
\hline Yes & 1.000 & & & \\
\hline No & $0.736(0.482-1.125)$ & 0.156 & & \\
\hline No partner & $0.663(0.183-2.399)$ & 0.532 & & \\
\hline \multicolumn{5}{|l|}{ Disclosure to other ${ }^{c}$} \\
\hline Yes & 1.000 & & 1.000 & \\
\hline No & $0.647(0.425-0.986)$ & 0.043 & $0.640(0.416-0.982)$ & 0.041 \\
\hline \multicolumn{5}{|l|}{ Any source of income } \\
\hline No & 1.000 & & & \\
\hline Yes & $0.542(0.224-1.316)$ & 0.176 & & \\
\hline
\end{tabular}

${ }^{a}$ Variables that had unadjusted $\mathrm{p}$-value $>0.10$ were not included in adjusted model

${ }^{\mathrm{b}}$ Partial or completed level of education

'We compared disclosure to other using the likelihood ratio test (LHRT) and the goodness of fit of a reduced model that considered only the disclosure to people who are not a woman's partner(s) with the final model that considered both disclosure to people other than a woman's partner(s) and marital status variables. We obtained a LHRT of 7.07 and a p-value of 0.0291. This suggests that the two models were not equivalent and that the final model had a better fit to the data

pregnant women with $\mathrm{uVL}$, in order to better inform their care and treatment.
Abbreviations

VL: Viral load; ART: Antiretroviral therapy; uVL: Undetectable VL; FLC: Friends for Life Circles; EC: Elite controllers. 


\section{Acknowledgements}

We would like to thank the FLC for Option B+ study team who were vital in the collection of the data and the study participants without whom this study would not have been possible.

\section{Authors' contributions}

GG wrote original draft. GR contributed to data curation. GG, AA, PW, SM RK, CN, JH, MGF and PM edited the manuscript. SM carried out the statistical analyses. JNM, IL, RK, JH, CN, ZN, MN, MGF and PM made contributions to the conception and design of the study and provided input on the manuscript. All authors reviewed and approved final manuscript.

\section{Funding}

These data are from the Friends for Life Circles for Option B+ study which was funded by NIH/Eunice Kennedy Shriver National Institute of Child Health and Human Development (NICHD) grant \# IR01HD080476-01.

\section{Availability of data and materials}

The datasets used and/or analysed during the current study are available from the corresponding author upon reasonable request. The study protocol has been provided under related files.

\section{Declarations}

\section{Ethics approval and consent to participate}

All study procedures were conducted in compliance with the relevant national laws and international regulatory requirements. Written informed consent was obtained from all study participants prior to any protocolspecified procedures being conducted. The study protocol, informed consent forms, and other study instruments administered to participants were reviewed and approved by the Joint Clinical Research Centre (JCRC) Institutional Review Board in Uganda; the Uganda National Council for Science and Technology (UNCST), Johns Hopkins University (JHU) and University of California San Francisco (UCSF) Ethics committees prior to participant enrolment or study procedures.

\section{Consent for publication}

Not applicable.

\section{Competing interests}

The authors declare that they have no competing interests.

\section{Author details}

${ }^{1}$ Makerere University - Johns Hopkins University Research Collaboration, P.O. Box 23491, Kampala, Uganda. ${ }^{2}$ Uganda Virus Research Institute, Entebbe, Uganda. ${ }^{3}$ Institute for Global Health Sciences, University of California, San Francisco, USA. ${ }^{4}$ Department of Pathology, Johns Hopkins University, School of Medicine, Baltimore, USA. ${ }^{5}$ Department of Paediatrics \& Child Health, School of Medicine, College of Health Sciences, Makerere University, Kampala, Uganda.

Received: 15 April 2021 Accepted: 17 August 2021

Published online: 04 September 2021

\section{References}

1. $\mathrm{WHO}$. WHO $/$ Consolidated guidelines on the use of antiretroviral drugs for treating and preventing HIV infection. Recommendations for a public health approach- second edition [Internet]. WHO. World Health Organization; 2016. https://www.who.int/hiv/pub/arv/arv-2016/en/. accessed 22 May 2019.

2. Unaids. The need for routine viral load testing [Internet]. 2016 [cited 2019 May 15]. https://www.unaids.org/sites/default/files/media_asset/JC2845_ en.pdf

3. Friends for Life Circles for Option B Plus - Full Text View - ClinicalTrials.gov [Internet]. [cited 2021 May 24]. https://clinicaltrials.gov/ct2/show/NCT02 515370

4. Laeyendecker O, Redd AD, Lutalo T, Gray RH, Wawer M, Ssempijja V, et al. Frequency of long-term nonprogressors in HIV-1 seroconverters From Rakai Uganda. J Acquir Immune Defic Syndr. 2009;52(3):316-9.

5. Kayongo A, Gonzalo-Gil E, Gümüşgöz E, Niwaha AJ, Semitala F, Kalyesubula R, et al. Brief report: identification of elite and viremic controllers from a large urban HIV Ambulatory Center in Kampala. Uganda J Acquir Immune Defic Syndr. 2018;79(3):394-8.

6. Olson AD, Meyer $L$, Prins M, Thiebaut $R$, Gurdasani $D$, Guiquet $M$, et al. An evaluation of HIV elite controller definitions within a large seroconverter cohort collaboration Okulicz JF. PLoS ONE. 2014;9(1):e86719.

7. Okulicz F, Elite J. Controllers and long-term nonprogressors: models for HIV vaccine development? J AIDS Clin Res. 2012;03(01):1.

8. Sivay MV, Fogel JM, Wang J, Zhang Y, Piwowar-Manning E, Clarke W, et al. Natural control of HIV infection in young women in South Africa: HPTN 068. HIV Clin Trials. 2018;19(5):202-8.

9. Naigino R, Makumbi F, Mukose A, et al. HIV status disclosure and associated outcomes among pregnant women enrolled in antiretroviral therapy in Uganda: a mixed methods study. Reprod Health. 2017;14:107. https://doi.org/10.1186/s12978-017-0367-5.

10. Masereka EM, Ngabirano TD, Osingada CP, et al. Increasing retention of HIV positive pregnant and breastfeeding mothers on option-b plus by upgrading and providing full time HIV services at a lower health facility in rural Uganda. BMC Public Health. 2019;19:950. https://doi.org/10.1186/ s12889-019-7280-5.

11. Sykes W, Van den Berg K, Jacobs G, Jauregui A, Roubinian N, Wiesner L, et al. Discovery of false elite controllers: HIV antibody-positive RNAnegative blood donors found to be on antiretroviral therapy. J Infect Dis. 2019;220(4):643-7.

12. Grabowski MK, Reynolds S, Kagaayi J, Gray R, Clarke W, Chang L, et al. The validity of self-reported antiretroviral use in persons living with HIV. AIDS. 2017;32(3):1

13. Fogel JM, Wang L, Parsons TL, Ou S-S, Piwowar-Manning E, Chen Y, et al. Undisclosed antiretroviral drug use in a multinational clinical trial (HIV Prevention Trials Network 052). J Infect Dis. 2013;208(10):1624-8.

14. European Collaborative Study. Time to undetectable viral load after highly active antiretroviral therapy initiation among hiv-infected pregnant women. Clin Infect Dis. 2007:44(12):1647-56.

\section{Publisher's Note}

Springer Nature remains neutral with regard to jurisdictional claims in published maps and institutional affiliations.

Ready to submit your research? Choose BMC and benefit from

- fast, convenient online submission

- thorough peer review by experienced researchers in your field

- rapid publication on acceptance

- support for research data, including large and complex data types

- gold Open Access which fosters wider collaboration and increased citations

- maximum visibility for your research: over $100 \mathrm{M}$ website views per year

At $\mathrm{BMC}$, research is always in progress.

Learn more biomedcentral.com/submissions 